\title{
Public Beliefs, Attitude and Practice of Voluntary Non-remunerated Blood Donation Among Resident in Sokoto, Nigeria
}

\author{
Aminu Umar Kaoje ${ }^{1, ~ *, ~ A b u b a k a r ~ U m a r ~ M u s a ~}{ }^{2}$, Nneka Christina Okafoagu ${ }^{3}$, Haruna Ibrahim ${ }^{1}$, \\ Mansur Olayinka Raji ${ }^{1}$, Umar Mohammed Ango ${ }^{1}$ \\ ${ }^{1}$ Department of Community Health, Usmanu Danfodiyo University, Sokoto, Nigeria \\ ${ }^{2}$ Department Haematology and Blood Transfusion, Usmanu Danfodiyo University, Sokoto, Nigeria \\ ${ }^{3}$ Department of Community Health, West Nile University of Nigeria, Abuja, Nigeria
}

Email address:

aukaoje@gmail.com (A. U. Kaoje)

${ }^{*}$ Corresponding author

To cite this article:

Aminu Umar Kaoje, Abubakar Umar Musa, Nneka Christina Okafoagu, Haruna Ibrahim, Mansur Olayinka Raji, Umar Mohammed Ango. Public Beliefs, Attitude and Practice of Voluntary Non-remunerated Blood Donation Among Resident in Sokoto, Nigeria. Central African Journal of Public Health. Vol. 3, No. 6, 2017, pp. 90-96. doi: 10.11648/j.cajph.20170306.11

Received: August 24, 2017; Accepted: September 8, 2017; Published: October 17, 2017

\begin{abstract}
The practice of blood donation and transfusion is life saving and in spite of extensive researches, an ideal blood substitute is yet to been found, therefore man will continue to depend on blood donated from fellow humans. The aim of the study is to assess public belief, attitude to and practices of voluntary non-remunerated blood donation among resident in Sokoto metropolis. This is a population-based descriptive cross-sectional study. Multistage sampling technique was applied to select the respondents. An interviewer-administered questionnaire was used to collect data. Skewed quantitative variables were summarised using median and inter-quartile range and categorical variables using frequencies and percentages. Chi square test of association and binary logistic regression analysis were performed. Results were presented in simple tables the result shows that the respondents' median age was 25 years, with interquartile range (IQR) of 21-29 years. Almost all (99\%) reported that blood donation is not contrary to their religious belief, and it was described as a form of service to humanity by $98 \%$. Although a large proportion (95\%) expressed appropriate beliefs and attitude to non-remunerated blood donation, only $25 \%$ of the respondents had ever donated. Respondents' gender $\left(\mathrm{X}^{2}=26.96, \mathrm{df}=1, P<0.001\right)$, marital status (Fischer test $\left.=8.36, P<0.01\right)$ and employment status (Fischer exact=13.77, $P<0.006$ ) showed statistically significant relationship with blood donation practice, but none of these factors did predict practice of voluntary blood donation. In conclusion, although large proportion demonstrated appropriate belief and attitude to voluntary non-remunerated blood donation, few ever donated blood. There is need to sensitize general public on its benefit to improve practice among general public in the metropolis.
\end{abstract}

Keywords: Voluntary Blood Donation, Beliefs, Attitudes, Practices, Sokoto

\section{Introduction}

The practice of blood donation and transfusion is life saving and has enabled management of chronic ailments and conducting complex surgical procedures. Despite extensive researches, an ideal blood substitute has not been found and man is still dependent on blood donated from fellow humans [1].

Generally, donated blood come from either voluntary nonremunerated donors, commercial donors or family members. Unlike developed countries, developing countries significant percentage of blood for transfusion depend largely on family replacement and paid blood donors [2]. Nigeria Federal Ministry of Health survey revealed that $25 \%$ of donated blood in public sector, is from commercial and $75 \%$ from family replacement donors while in private sector, $75 \%$ and $25 \%$ were commercial and family replacement donors respectively and voluntary donors were negligible in both sectors [3]. A study by Al-Drees et al also revealed that most of the blood donors are direct donors instead of volunteer donors, paid donors, or autologous donors while lot of 
community members are non-donors [4].

Because of rise in life expectancy and implementation of new and sophisticated surgical and therapeutic methods requiring large amount of blood, demand for blood in most countries continues to increase [5]. Blood donation is widely described as an altruistic behaviour, and Healy et al identified the religious beliefs of donors as indicators of the altruistic behaviours [6].

\section{Materials and Method}

\subsection{Study Area and Population}

The study was conducted in Sokoto metropolis, which comprised of four Local Government Areas (LGA) with population size of 269,525 inhabitants. The residents are predominantly Muslims and largely Hausa/Fulani however there are other tribes in minority from other part of the country. All head of households, other residents aged 18 years and above who were willing to participate in the study and present at the time of data collection were included.

\subsection{Study Design}

A descriptive cross-sectional study design was used to assess public belief, attitudes and practices of non-remunerated voluntary blood donation among residents of Sokoto metropolis.

\subsection{Sample Size Determination and Sampling Technique}

A representative sample size of 271 was obtained using formula for descriptive study design [7], $\mathrm{n}=\mathrm{Z}_{\alpha}^{2} \times \mathrm{pq} / \mathrm{d}^{2}$ where $\mathrm{n}$, is sample size; $Z_{\alpha}$ is standard normal deviate at alpha error corresponding to confidence value of 1.96 ; $p$ is the proportion of factor of interest under study in the previous study and $q$ is complimentary probability of $\mathrm{p}$ while $\mathrm{d}$ is level of precision set at alpha value of $5 \%(0.05)$. A multistage sampling technique was used to select the study respondents. In the first stage, two LGAs within the metropolis were selected using simple random sampling technique method (Balloting technique). In stage 2, three political wards each from the two selected LGAs were selected using simple random sampling technique (Balloting technique) and stage 3, five districts each from the selected political ward were selected using simple random sampling technique (Balloting technique). In the fourth stage, a required sample size for each selected district was allotted using probability proportional to size (PPS) based on the population distribution of the selected districts. At stage 5, houses, shops, offices and eating points were selected using a systematic sampling method. Where in the selected house, or shop or office, the eligible person refused to participate, the next sampling unit was selected.

\subsection{Data Collection and Analysis}

Research assistants used close-ended questionnaires to collect the data through interviews. The questionnaire was pre-tested on twenty volunteers from a district that was not part of the main study site. The data was analysed using statistical package for social science (SPSS) version 20.0. The mean and standard deviation was calculated for the continuous data while the categorical data were expressed in frequency and percentages. The respondents' responses to questions on attitude were scored and graded at the end of data collection. Each appropriate response on respondents' attitude to blood donation was awarded 1 mark while zero (0) was awarded to inappropriate response. The respondents' attitude was graded as either positive or Negative. Aggregate scores of less than $50 \%$; and equal to or greater than $50 \%$ were adjudged negative and positive attitudes respectively. At the end of scoring, the proportion of respondents with negative and positive attitude was determined. Chi square test of association was used to determine the association between respondents' socio-demographic characteristics and Belief, Attitude and Practice of blood donation. Binary logistic regression analysis was carried out to identify respondents' characteristics that were key determinants for their Attitude and Practice of voluntary blood donation.

\subsection{Ethical Consideration}

Ethical clearance was sought and obtained from the Research Ethics Committee of Sokoto state Ministry of Health. Permission to carry out the study was obtained from the Ministry for Local Government and Community Development and District Heads of selected districts. In addition, individual informed consent was obtained before the questionnaire was administered.

\section{Results}

Table 1. Socio Demographic Characteristics of the Study Respondents.

\begin{tabular}{|c|c|c|}
\hline Variables & Number & Percentage \\
\hline \multicolumn{3}{|c|}{ AGE GROUPS (YEARS) } \\
\hline $20-29$ & 178 & 65.7 \\
\hline $30-39$ & 55 & 20.3 \\
\hline $40-49$ & 38 & 14.0 \\
\hline \multicolumn{3}{|l|}{ SEX } \\
\hline Male & 178 & 65.7 \\
\hline Female & 93 & 34.3 \\
\hline \multicolumn{3}{|c|}{ MARITAL STATUS } \\
\hline Married & 190 & 70.4 \\
\hline Single & 77 & 28.5 \\
\hline Widow & 3 & 1.1 \\
\hline \multicolumn{3}{|l|}{ RELIGION } \\
\hline Islam & 225 & 94.1 \\
\hline Christianity & 16 & 5.9 \\
\hline \multicolumn{3}{|l|}{ ETHNICITY } \\
\hline Hausa & 237 & 87.5 \\
\hline Yoruba & 17 & 6.3 \\
\hline Igbo & 6 & 2.2 \\
\hline Others & 11 & 4.1 \\
\hline \multicolumn{3}{|l|}{ JOB STATUS } \\
\hline Employed & 39 & 14.4 \\
\hline Self-employed & 31 & 11.4 \\
\hline Unemployed & 7 & 2.6 \\
\hline Housewife & 44 & 16.2 \\
\hline Student & 150 & 55.4 \\
\hline \multicolumn{3}{|l|}{ OCCUPATION } \\
\hline Formal sector & 43 & 42.1 \\
\hline Informal sector & 59 & 57.9 \\
\hline
\end{tabular}


Table 1 shows median age to be 25 years, IQR 21 to 29 . Majority 178 (65.7\%) was aged between 20-29 years while those aged between 40-49 years were very few, 38 (14\%). Most of the respondents were male $178(65.7 \%)$ and female accounted for the remaining proportion. A large number 190
(70.4\%) were married while the singles and widow accounted for $77(28.5 \%)$ and $3(1.1 \%)$ respectively. A large number $150(55.4 \%)$ of respondents were student while the government employee accounted for 39 (14.4\%).

Table 2. Awareness of Blood Donation Service CENTRE in Sokoto.

\begin{tabular}{lcc}
\hline Variables & Frequency \\
\hline Are you aware of Walk-in blood donation centre in Sokoto & 143 \\
Yes & 126 \\
No & 53 \\
If yes, where is the centre located in Sokoto & 80 \\
Inside UDUTH & 32 \\
Inside Specialist Hospital & 31 \\
Epidemiology unit near Specialist hospital & 56.7 \\
Source of your information & 29.9 \\
Radio & 21.7 \\
Newspaper & 11 \\
Friends & 89 \\
Relatives & 20.1 \\
Others & 7.6 \\
\hline
\end{tabular}

UDUTH= Usmanu Danfodiyo University Teaching Hospital.

Result in table 2 shows that majority (53.0\%) of the respondents are aware that there is walk-in blood donation centre in Sokoto metropolis but only few of them $(22 \%)$ correctly knew where the centre is located within the metropolis.

Table 3. Some Aspects of Respondents' Belief and Attitude to Voluntary Blood Donation.

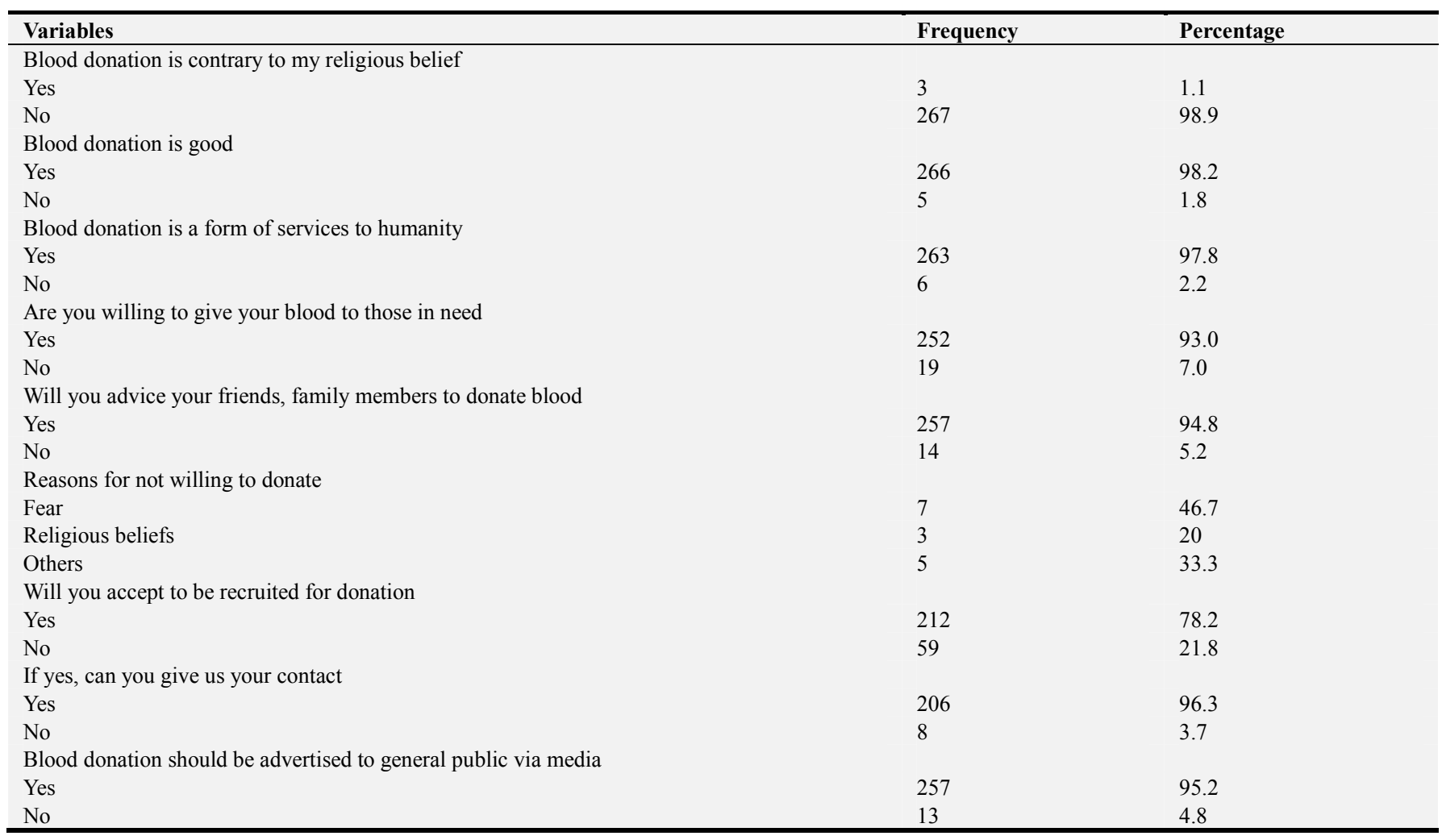

Table 3 shows that almost all the respondents' 267 (99\%) reported that blood donation is not contrary to their religious belief, and that blood donation is good 266 (98\%) and is a form of service to humanity 263 (98\%). Two hundred and fifty two $(93 \%)$ are willing to donate blood while those that are not willing mentioned fear of losing much blood and their religious as some of their reasons. 


\section{Respondents' attitude}

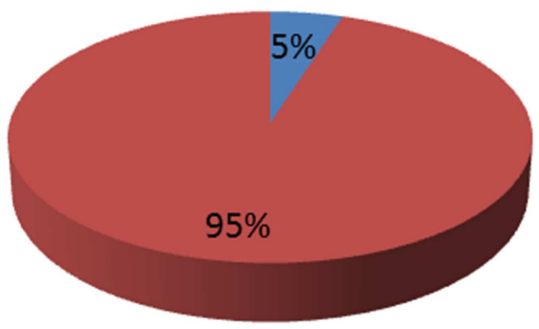

Negative

attitude

Positive attitude

Figure 1. Respondents' Attitude to Voluntary Blood Donation.

Figure 1 result shows that a very large number 257 (95\%) have positive (appropriate) attitude to voluntary blood donation and very little proportion reported inappropriate attitude.

Table 4. Practices of Voluntary Non-remunerated Blood Donation.

\begin{tabular}{lll}
\hline Variables & Frequency & Percentage \\
\hline Have you ever donated your blood & 69 & 25.5 \\
Yes & 202 & 74.5 \\
No & & 88.1 \\
Do you have desire or intent to donate blood now and in future & 238 & 11.9 \\
Yes & 32 & 23.2 \\
No & & 69.6 \\
If ever donated, what was the circumstance of the donation & 16 & 7.2 \\
Donated voluntarily & 48 & 68.7 \\
Donated for a friend/relative & 5 & 20.3 \\
Donate for money & & 14.5 \\
Motivation for donation & 44 & 44.8 \\
Torve humanity & 13 & 43.6 \\
Others my family & 9 & 7.9 \\
Reasons For Not Ever Donated & & 3.7 \\
Not approached & 158 & \\
None of my relatives need blood & 154 & 28 \\
No enough blood to donate & 13 & \\
Fear of knowing my status & & \\
\hline
\end{tabular}

Table 4 result shows only small proportion of the respondents, $69(25.5 \%)$ ever donated blood before but majority 238 (88.1\%) have the desire to donate now and in the future. A large proportion of those that donated their blood $48(69.6 \%)$ donated to friends and family members.

Table 5. Relationship Between Socio-demographic Characteristics and Respondents'Attitude to Voluntary Blood donation.

\begin{tabular}{|c|c|c|c|}
\hline & Attitude to voluntary & & \\
\hline VARIABLES & Inappropriate, f (\%) & Appropriate, f (\%) & Test statistic \& p value \\
\hline \multicolumn{4}{|l|}{ Age group (years) } \\
\hline $20-29$ & $4(30.8)$ & $174(67.4)$ & \multirow{3}{*}{$\begin{array}{l}\text { Fischer exact test }=9.61 \\
P<0.03\end{array}$} \\
\hline $30-39$ & $5(38.5)$ & $50(19.4)$ & \\
\hline $40-49$ & $4(30.8)$ & $34(13.2)$ & \\
\hline SEX & & & \multirow{3}{*}{$\begin{array}{l}\mathrm{LR}=0.08, \mathrm{df}=1 \\
P>0.78\end{array}$} \\
\hline Male & $9(69.2)$ & $169(65.5)$ & \\
\hline Female & $4(30.8)$ & $89(34.5)$ & \\
\hline MARITAL STATUS & & & \multirow{4}{*}{$\begin{array}{l}\text { Fischer exact test }=2.1 \\
P=0.32\end{array}$} \\
\hline Single never married & $6(46.2)$ & $71(27.6)$ & \\
\hline Married & $7(53.8)$ & $183(71.2)$ & \\
\hline Widow & 0 & $3(1.2)$ & \\
\hline RELIGION & & & \multirow{4}{*}{$\begin{array}{l}\mathrm{LR}=4.51, \mathrm{df}=1 \\
P>0.03 \\
\text { Fischer exact test }=4.01 \\
P=0.19\end{array}$} \\
\hline Islam & $10(76.9)$ & $245(95.0)$ & \\
\hline ETHNICITY & & $15(0.0)$ & \\
\hline Hausa/Fulani & $10(76.9)$ & $227(88.0)$ & \\
\hline
\end{tabular}




\begin{tabular}{llll}
\hline & \multicolumn{2}{l}{ Attitude to voluntary blood donation } & Test statistic \& p value \\
\hline VARIABLES & Inappropriate, $\mathbf{f}(\%)$ & Appropriate, $\mathbf{f}(\%)$ & \\
\hline Yoruba & $1(7.7)$ & $16(6.2)$ & \\
Ibo & $1(7.7)$ & $5(1.9)$ & \\
Others & $1(7.7)$ & $10(3.9)$ & \\
JOB STATUS & & & \\
Employed & $5(38.5)$ & $34(13.2)$ & Fischer exact test $=5.23$ \\
Self-employed & $1(7.7)$ & $30(11.6)$ & $P=0.20$ \\
Unemployed & 0 & $7(2.7)$ & \\
Housewife & $2(15.4)$ & $42(16.3)$ & Fischer exact test $=8.34$ \\
Student & $5(38.5)$ & $145(56.2)$ & $P=0.17$ \\
OCCUPATION & & $37(39.8)$ & \\
Formal sector & $6(66.7)$ & $51(54.9)$ & \\
Informal & $3(33.3)$ &
\end{tabular}

$\mathrm{LR}=$ likelihood ratio; $\mathrm{f}=$ frequency; $\%=$ Percent

Table 5 result of cross tabulation analysis using chi squared test to determine existence of relationship between sociodemographic characteristics and respondents' attitude to voluntary Blood donation, shows that only age (Fischer exact test $=9.61, \mathrm{P}=0.03$ ) and religion $\mathrm{LR}=4.51, \mathrm{df}=, 1 \mathrm{P}>0.03$ ) were statistically significant. None of these variables did predict the respondents' attitude to voluntary blood donation.

Table 6. Relationship Between Socio-demographic Characteristics and Practice of Voluntary Blood Donation.

\begin{tabular}{|c|c|c|c|}
\hline \multirow[b]{2}{*}{ VARIABLES } & \multicolumn{3}{|c|}{ Practice of voluntary blood donation } \\
\hline & Yes, f $(\%)$ & No, $f(\%)$ & Test statistic \& p value \\
\hline \multicolumn{4}{|l|}{ Age group (years) } \\
\hline $20-29$ & $54(78.6)$ & $150(74.3)$ & \multirow{3}{*}{$\begin{array}{l}\text { Fischer exact test }=2.23 \\
P=0.70\end{array}$} \\
\hline $30-39$ & $12(17.4)$ & $43(21.3)$ & \\
\hline $40-49$ & $3(4.3)$ & $9(4.5)$ & \\
\hline SEX & & & \multirow{3}{*}{$\begin{array}{l}\mathrm{X}^{2}=26.96, \mathrm{df}=1 \\
P<0.000 \mathrm{I}\end{array}$} \\
\hline Male & $63(91.1)$ & $115(56.9)$ & \\
\hline Female & $6(8.9)$ & $87(43.1)$ & \\
\hline \multicolumn{4}{|l|}{ MARITAL STATUS } \\
\hline Married & $11(15.9)$ & $66(32.8)$ & \multirow{3}{*}{$\begin{array}{l}\text { Fischer exact test }=8.36 \\
P<0.01\end{array}$} \\
\hline Single & $56(84.1)$ & $132(65.7)$ & \\
\hline Widow & 0 & $3(1.5)$ & \\
\hline \multicolumn{4}{|l|}{ RELIGION } \\
\hline Islam & $67(97.1)$ & $188(93.1)$ & \multirow{2}{*}{$\begin{array}{l}\mathrm{LR}=1.73, \mathrm{df}=1 \\
P>0.19\end{array}$} \\
\hline Christianity & $2(2.9)$ & $14(6.9)$ & \\
\hline \multicolumn{4}{|l|}{ ETHNICITY } \\
\hline Hausa/Fulani & $64(92.8)$ & $173(85.6)$ & \multirow{4}{*}{$\begin{array}{l}\text { Fischer exact test }=2.08 \\
P=0.58\end{array}$} \\
\hline Yoruba & $3(4.3)$ & $14(6.9)$ & \\
\hline Ibo & $1(1.4)$ & $5(2.5)$ & \\
\hline Others & $1(1.4)$ & $10(5.0)$ & \\
\hline \multicolumn{4}{|l|}{ JOB STATUS } \\
\hline Employed & $14(20.3)$ & $25(12.4)$ & \multirow{5}{*}{$\begin{array}{l}\text { Fischer exact test }=13.77 \\
P<0.006\end{array}$} \\
\hline Self-employed & $11(15.9)$ & $20(9.9)$ & \\
\hline Unemployed & $1(1.4)$ & $6(3.0)$ & \\
\hline Housewife & $3(4.3)$ & $43(20.3)$ & \\
\hline Student & $40(58.0)$ & $110(54.5)$ & \\
\hline OCCUPATION & & & \multirow{3}{*}{$\begin{array}{l}\text { Fischer exact test }=2.75 \\
P=0.90\end{array}$} \\
\hline Formal sector & $15(42.8)$ & $30(41.8)$ & \\
\hline Informal sector & $20(57.2)$ & $39(58.2)$ & \\
\hline ATTITUDE & & & \multirow{3}{*}{$\begin{array}{l}\mathrm{LR}=2.85, \mathrm{df}=1 \\
P>0.09\end{array}$} \\
\hline Inappropriate & $1(1.4)$ & $12(5.9)$ & \\
\hline Appropriate & $68(98.6)$ & $190(94.1)$ & \\
\hline
\end{tabular}

$\mathrm{f}=$ frequency; $\%=$ Percent.

Table 6 result of chi squared analysis shows that $\operatorname{sex}\left(X^{2}=\right.$ 26.96, df $=1, \mathrm{P}<0.000$ ), marital status (Fischer exact test $=8.36, \mathrm{P}=0.01$ ) and respondents' job status (Fischer exact test $=13.77, \mathrm{P}=0.006$ ) were statistically significant to Practice of Voluntary Blood Donation. Logistic regression analysis did show that none of the respondents' sociodemographic variables did significantly predict whether the respondents would donate blood voluntarily or not.

\section{Discussion}

This study primarily focused on public belief, attitude and practice towards voluntary, unremunerated blood donation. The World Health Organization introduced the 100\% unpaid, 
voluntary blood donation policy in 1997 . World Blood Donor Day was established at the $58^{\text {th }}$ World Health Assembly in May 2005 by WHO's 192 Member States, to urge all countries in the to thank blood donors, promote voluntary, unpaid blood donations and ensure safe supplies of blood for all. As many countries have reached $100 \%$ unpaid voluntary blood donation, only 17 developing countries made the list [8].

This study showed that a majority of the respondents thought that blood donation was good and not contrary to their belief. This is also reflected in findings in a study in Benin city [9]. The obstacle of belief being a barrier to blood donation can therefore be said to be removed paving the way for more sensitization on blood donation.

Although majority of the respondents had positive attitude towards blood donation, the practice of voluntary blood donation was abysmal. Most of the respondents were within the age range of donation but only $25 \%$ ever donated blood, which is just $3 \%$ above what was reported in a study in Benin city where only $22.1 \%$ did so [8] and in Gujarat, India where only $39 \%$ ever donated voluntary [10]. Of those that donated, majority donated for relatives while very few did so voluntarily. This raises concern for the availability of life saving blood in times of emergency and the fact that the safest blood donors are found among people who donate their blood voluntarily as the risk of transfusion transmissible diseases is highest with the blood procured from remunerated donors [11-13]. Studies in Pakistan and Peshawar also found that majority of the donors did so for families while only few donated blood voluntarily [14, 15]. In this study, more than three quarters of the respondents accepted to be recruited for donation and a majority of them gave their contacts. This is encouraging and shows a high level of commitment to their acceptance to providing sufficient blood to our teaming populace. This is contrary to findings in a study in Benin City Nigeria where very few of the respondents accepted to be recruited for blood donation and even fewer gave their contacts afterwards [9]. The major reason given by those who had never donated was that they had never been approached. This underscores the need for mass sensitization to encourage the populace to voluntarily donate blood at the blood banks. Studies in Benin city and Peshawar also cited similar reasons for not donating $[9,15]$.

There was a significant relationship between gender and blood donation practice. Males in our society were found to be more likely to donate blood compared to the women. This is not surprising as women are deterred by physiological conditions such as pregnancy and menstruation limiting their chances to donate blood. This concurs with the WHO report 2011 that there are more male donors in Nigeria [16]. Similar studies in Saudi Arabia and India also showed that most of the donors were males $[17,18]$. This buttresses the need for more enlightenment on blood donation for the female populace as being a female should not be a limiting factor to blood donation.

\section{Conclusion}

In conclusion, the study found that a large proportion of the respondents expressed positive attitude and beliefs to blood donation. In spite of good awareness, positive attitude and beliefs to blood donation, the practice of voluntary blood donation is still low as less than one third had ever donated. A significant proportion of the respondents expressed willingness and intent to donate now and in the near future. Respondents' gender, marital status and job status showed statistically significant association with voluntary blood donation but none did predict the donation behaviour and practice.

\section{Acknowledgements}

The authors acknowledged the kind support of the final year medical students of Usmanu Danfodiyo University, Sokoto that administered the questionnaires and ensured quality assurance through out the process.

\section{Authors' Contribution}

AUK: is the lead researcher, conceptualized the study and design

AUM and GSJ: Did the entire data analysis and interpretation of the result

NCO: Wrote the discussion and conclusion aspect of the article

MOR: Wrote the introduction and abstract

UMA: Coordinated field data collection and entry into computer statistical software

\section{Conflict of Interest}

All authors do not have any possible conflict of interest.

\section{References}

[1] Dutta AB. Transfusion Practice Clinical Aspects and Applications In: Blood Banking and Transfusion $1^{\text {st }}$ ed. New Delhi: CBS Publishers. 2006; 213-321.

[2] Enosolease ME, Imarengiaye CO, Awodu OA. Donor blood procurement and utilization at the University of Benin Teaching Hospital, Benin City. Afr J Reprod Health. 2004, 8: 59-63.

[3] Nigeria National Blood Transfusion Service. Nigerian National Blood Policy; Federal Ministry of Health Abuja 2006; 1-16.

[4] Al-Drees AM. Attitude, belief and knowledge about blood donation and transfusion in Saudi population. Pakistan Journal of Medical Sciences. 2008, 24 (1): 74-79.

[5] Riley W, Schwei M, McCullough J. The United States potential blood donor pool: estimating the prevalence of donor-exclusion factors on the pool of potential donors. Transfusion. 2007, 47: 1180-1188.

[6] Healy, K. Embedded altruism: Blood collection regimes and the European Union's donor population. American Journal of Sociology. 2000; 105: 1633-1657. 
[7] Araoye OM. Research methodology with statistics for Health and Social Sciences. Ilorin, Mathadex Publishers. 2003: 119.

[8] World Health Organization. 'Most countries fall short of ensuring a safe blood supply but some progress made'. World Blood Donor Day: Geneva. 2006.

[9] Benedict N, Usimenahon A, and Alexander IN. Knowledge, Attitude and Practice of voluntary blood donation among health care workers at the University of Benin Teaching Hospital, Benin City, Nigeria. Journal of Blood Transfusion. 2013, Pg. 6.

[10] Mullah F, Kumar D, Antani D, and Gupta M. Study of knowledge, perceptions and practices related to blood donation among the healthcare support staff of a tertiary care hospital in Gujarat, India," The Online Journal of Health and Allied Sciences. 2013, Vol. 12, No 1.

[11] Eastlund T. "Monetary blood donation incentives and the risk of transfusion- transmitted infection," Transfusion. 1998, Vol. 38, No 9; pp. 874-882.

[12] Van der Poel CL, Seifried E and Schaasberg WP. "Paying for blood donations: still a risk?" Vox Sanguinis. 2002, Vol. 83, No. 4, pp. 285-293.
[13] Ejele OA, Erhabor O, and Nwauche CA. "The risk of transfusion-transmissible viral infections in the Niger-Delta area of Nigeria." Sahel Medical Journal. 2005, Vol. 8, No. 1; pp 16-19.

[14] Waheed U, khan H, Satti HS, Ansari MA, Malik MA, Zaheer HA. Prevalence of transfusion transmitted infections among blood donors of a Teaching Hospital in Islamabad. Ann. Pakinst. Med. Sci. 2012; 8(4): 236-9.

[15] Sethi H, Ayaz M, Niaz P, Sahidullah G, Aziz S, Shah N, et al. Awareness of voluntary blood donation among the general public visiting a rural Hospital of Peshawar, Khyber Pakhtunkhwa. Journal of Medical Students. 2015; 1(2), 3-11.

[16] WHO report on Gender distribution of blood donors by country.” Data Reported by WHO Global Database on Blood Safety. 2011.

[17] Lowe KC, Ferguson E. Benefits and risk perceptions in Transfusion Medicine: blood and blood substitutes. J Intern Med. May 2003; 253 (5): 498-507.

[18] Mousavi F, Tavabi AA, Golestan B, Ammar-Saeedi E, Kashani H, Tabataei R, et al. Knowledge, attitude and practice towards blood donation in Iranian population. Transfus Med. Oct 2011; 21(5): 308-17. 